\title{
ROLE OF MEDIA IN DISASTER MANAGEMENT
}

\author{
Asst. Prof. Neelam Kapoor ${ }^{1 *}$ \\ *17-Laxmi Nivas Near Chaman Hotel Nayapura Kota, Rajasthan
}

*Corresponding Author: -

\begin{abstract}
: -
The media forges a direct link between the public and emergency organizations and plays a very important role in disseminating vital information to the public before, during and after disasters. The media assists in the management of disasters by educating the public about disasters; warning of hazards; gathering and transmitting information about affected areas; alerting government officials, relief organizations and the public to specific needs; and facilitating discussions about disaster preparedness and response for continuous improvement. To help the media fulfill these roles, direct working relationships between the media and disaster management organizations should be established and maintained. Experience shows that regular interactions with the media before a disaster strikes, aids the effective flow of information and lays the groundwork for effective working relationships in the aftermath of a disaster. 1 The Press Day on November 16,

2000 was observed with the theme of "Role of Media in Disaster Management - Preparing People to Cope with Disasters." A National Seminar was organised at Vigyan Bhawan, New Delhi, which was inaugurated by the President of India. In his inaugural address, the Hon'ble President emphasized the need for disseminating preparedness aspects of disaster management among all sections of society and making special provisions for the more vulnerable sections of the community viz. women and children.
\end{abstract}

Keywords: Disaster, Satellite Radio, Mass Media \& ICT.

\section{(c) $(\$)$}




\section{TERMINOLOGY}

MASS MEDIA: Communication channels used for mass dissemination of information to the public.

ELECTRONIC MEDIA: Channels that broadcast information to mass audiences by electronic means, through radio and television for example.

PRINT MEDIA: Channels that disseminate information to the public in print format, such as newspapers, journals and magazines.

SATELLITE RADIO: A more sophisticated kind of radio that utilizes satellite technology to broadcast audio information from orbiting satellites directly to the receiver.

\section{THE ROLE OF MEDIA IN DISASTER MANAGEMENT TYPES OF MEDIA}

Two main types of mass media exist, namely, the electronic and print media.

\section{THE ELECTRONIC MEDIA}

THE RADIO The radio is the most popular and widespread information tool used in disaster management due to its affordability and widespread reach. Radios are more readily available in homes, cars, schools and at the workplace and can quickly and easily transmit information to the public through disaster preparedness documentaries, commercials designed to build awareness, discussion groups and interviews, radio dramas and call in programmes. The radio takes information directly to people from all walks of life, quickly and easily, even the very poor in the most remote rural village. Satellite radios can play a key role during the disaster warning and disaster recovery phases. Its key advantage is the ability to work even outside of areas not covered by normal radio channels. Satellite radio can also be of help when the transmission towers of the normal radio channels are damaged in disaster.

THE TELEVISION The Television is a powerful tool in broadcasting disaster warnings, ands a powerful tool in broadcasting disaster warnings, and is widely used in many countries, with growing popularity. The visual impact of the television provides tremendous opportunity for disseminating messages with great impact on the viewing public because of the realistic combination of picture and sound

\section{THE PRINT MEDIA}

THE NEWSPAPER The Newspaper is one of the oldest means of communication that can still be relied on. It can be used for both early warnings as well as for recovery messages. The good thing is that the newspaper is widely circulated and can be made to reach the most remote areas by using helicopters to aid the distribution process.

OTHER PRINTED MATERIAL Magazines and journals target a specific audience, for example contractors/builders, academics or farmers. It is therefore an effective way to reach targeted populations with specific disaster-related information.

\section{THE MEDIA PLAY A SPECIAL ROLE IN DISASTER MANAGEMENT}

The media plays an integral and vital role in the management of disasters. Usage of satellite imagery facilitates speedy transmission of information around the globe, and this has put tremendous power in the hands of news Introduction to Disaster Management reporters to influence global public opinion. Since disasters are a significant source of news and capture the attention of populations worldwide, the media provides tremendous visibility for disaster-related issues and, if used properly, can aid the process of disaster management in the following ways

INCREASED LOBBYING The media can increase lobbying for political commitment, to make national leaders more responsive to the unique needs of vulnerable communities and special populations (such as the elderly and disabled) by increasing visibility of related issues through consistent reporting. By applying pressure on public officials, the media can help effect positive change when for unique areas that would otherwise have been ignored.

AID PRIORITIZATION OF DISASTER RISK ISSUES The media can influence the government to prioritize disaster risk issues, thereby ensuring that "self serving" political interests are not emphasized at the expense of the wider population. For example, the media may expose excessive and inefficient expenditure to relocate persons from vulnerable areas just before a general election with a view to secure votes, while little or no attention is given to replenishing the stock of relief supplies in the national warehouse for distribution in the event of a disaster. This kind of exposure facilitates more prudent and balanced prioritization of disaster risk issues.

\section{IMPACT OF THE MEDIA}

The media is a mere tool in the hands of the disaster management professional and can, therefore, yield positive or negative results depending on how it is used.

\section{POSITIVE EFFECTS OF THE MEDIA}

1. The media is usually the first to define the event as an official disaster. They inform the public about it and therefore heighten awareness. This resulting awareness influences public opinion about how the disaster is being managed and often determines the level of attention Introduction to Disaster Management that relief agencies pay to the particular disaster. 
2. The media provides instantaneous information and are considered to be trusted sources especially at the local level, where the news media have a "vested interest" in the home town. The network's continuous and factual coverage of incidents and post-disaster events can aid decision making and response immediately after a disaster, thereby saving lives and property.

3. The media is an invaluable asset in times of a disaster by disseminating information about public safety, giving details useful details on areas such as impassable roadways and downed utility lines. Other important public health concerns are usually addressed by issuing water safety advisories and providing information about sites where medical help is available for the public.

4. In the absence of telephones and other mechanisms for communicating with the world outside an affected area, the news media provides: the affected population with much needed information and the outside world with a glimpse of what that affected community is dealing with.

\section{NEGATIVE EFFECTS OF THE MEDIA}

By developing an awareness of both the positive and negative aspects of disaster coverage, you can be better prepared to view both the print and electronic media in a more realistic manner.

1. The media may exaggerate some elements of the disaster and create unnecessary panic.

2. The media's inaccurate portrayal of human behavior during and after disasters may create a very dramatic and exciting, but only partially truthful story. For instance, it is not uncommon to see footage of people looting after a disaster on all news networks, but most viewers may not realize that all the networks were covering the same store being looted. As a result, people may feel that widespread and uncontrollable looting is taking place in the affected area(s) which may not be true at all.

3. Influential politicians may manipulate the media for personal or political gains. For example, Hurricane Dean significantly affected the island of Jamaica a few weeks before the 2007 general elections. The electronic media consistently showed members of a particular political party issuing relief items to the poor, which sent a subliminal message that the political party in question was more responsive to the needs of the people than the other. Incidentally, the political party (that was portrayed in a positive light by the media) won the elections and now forms the new government of Jamaica.

4. News reporters may provide biased coverage for purposes of sensationalism by capturing horrific devastation on a street, choosing to ignore that on the opposite side of the street all the houses are intact with minor damage. This kind of "irresponsible journalism" may lead to the deployment of unnecessary and inappropriate resources to moderately affected areas thereby depriving the more severely Introduction to Disaster Management affected areas of well needed aid.

5. Media representatives often converge on a high-profile event creating tremendous "congestion" in the affected area. This influx of individuals with needs into an already burdened area can be overwhelming, which may hinder or compromise search and rescue operations, jeopardize rescuer safety and hamper the provision of care needed by the critically ill and injured. We see from the above discussion that the media can play a very positive and important role in times of disaster, but can likewise hinder the response and recovery process. With this in mind, it is important to recognize that convergence of the media generally occurs after national disasters and, as such, a plan to effectively manage the media should be part of every disaster plan and standard operating procedures.

\section{REFERENCES}

[1].Ministry Of Home Affairs, Government Of India (2009)“National Policy on Disaster Management” New Delhi, p.20.

[2].Department of Agriculture and Cooperation Ministry of Agriculture Government of India (2001) "High Powered Committee on Disaster Management" New Delhi, p-205.

[3].Virtual University for the Small States of the Commonwealth (VUSSC) Commonwealth of Learning (COL) (2011) "Introduction to Disaster Management" Canada, pp-119-120.

[4].National Disaster Management Authority (2009) “2nd INDIAN DISASTER MANAGEMENT CONGRESS”, New Delhi, pp-185-187.

[5].Virtual University for the Small States of the Commonwealth (VUSSC) Commonwealth of Learning (COL) 2011"Introduction to Disaster Management" Canada, pp-122. 